Service social

\title{
Travail et soins aux proches dépendants, par Nancy Guberman, Pierre Maheu et Chantal Maillé, Montréal, Éditions du remue-ménage, 1993, 195 pages.
}

\section{Solange Matte}

Volume 42, numéro 3, 1993

Perspectives théoriques

URI : https://id.erudit.org/iderudit/706637ar

DOI : https://doi.org/10.7202/706637ar

Aller au sommaire du numéro

Éditeur(s)

École de service social de l'Université Laval

ISSN

1708-1734 (numérique)

Découvrir la revue

Citer ce compte rendu

Matte, S. (1993). Compte rendu de [Travail et soins aux proches dépendants, par Nancy Guberman, Pierre Maheu et Chantal Maillé, Montréal, Éditions du remue-ménage, 1993, 195 pages.] Service social, 42(3), 155-156.

https://doi.org/10.7202/706637ar d'utilisation que vous pouvez consulter en ligne.

https://apropos.erudit.org/fr/usagers/politique-dutilisation/ 
Voilà un livre qui présente certains aspects de la sécurité sociale, mais qui surtout a le mérite d'organiser dans un modèle relativement simple un grand nombre de faits disparates et dispersés. Le non-spécialiste y trouvera donc son profit et découvrira un ensemble intégré et accessible de connaissances de base, alors que les plus avertis auront plaisir à pousser plus loin le questionnement et les débats de fond qu'il soulève.

René AUCLAIR

École de service social

Université Laval

\section{TRAVAIL ET SOINS AUX PROCHES DÉPENDANTS}

Nancy Guberman, Pierre Maheu et Chantal Maillé Montréal, Éditions du remue-ménage, 1993, 195 pages.

En cette fin d'État-providence, l'État a de plus en plus recours aux personnes, aux familles, aux communautés et au secteur privé pour la prise en charge des personnes dépendantes. Dans les familles qui assument cette prise en charge, la tâche est pour la plus grande part dévolue aux femmes, même si, dans certains cas de plus en plus nombreux, celles-ci doivent aussi occuper un emploi afin de subvenir aux besoins pécuniaires de la famille. On constate que les conditions existantes sur le marché du travail ont une influence importante dans la multiplication d'un problème social: la multiplication de personnes dépendantes à prendre en charge. L'entreprise privée sera appelée de plus en plus à soutenir ses employés dans leurs besoins particuliers. La lecture de ce livre permet d'accéder à une vision globale de la situation. Les informations qu'il regroupe proviennent de deux sources: des données de recherche sur la prise en charge des personnes adultes dépendantes accumulées depuis 1986 et une recherche menée dans le monde du travail américain et canadien. Cet ouvrage démontre l'importance de tenir compte, dans les politiques et programmes touchant la famille et la santé, des difficultés majeures que vivent les familles, en particulier les femmes devant concilier des tâches et des rôles souvent conflictuels. II vient donc alimenter un aspect peu exploré de la problématique des aidants naturels, celui de la conciliation des exigences d'un emploi et de la prise en charge d'un proche dépendant.

Travail et soins aux proches dépendants comporte trois chapitres. Le premier révèle la réalité du phénomène de la prise en charge $d^{\prime}$ un proche dépendant en présentant une définition des personnes dépendantes, une description du rôle joué par les familles, la signification de cette prise 
en charge dans le quotidien et les motifs qui amènent les familles (les femmes surtout) à assumer cette prise en charge. Le deuxième présente les résultats $d^{\prime}$ une recherche effectuée auprès de vingt-cinq femmes soignantes occupant un emploi salarié. Abondamment illustré par leurs témoignages, il traite de leurs difficultés à concilier leur emploi et la prise en charge d'un proche, des formes d'aménagement privilégiées, des conditions existant dans leurs milieux de travail, des facteurs qui influencent ou déterminent l'équilibre entre les différentes sphères de leur vie ainsi que des avantages et des limites des diverses formes d'aménagement pour ces soignantes. Au dernier chapitre il est question de partenariat entreprise / employés. Les données présentées sont issues d'enquêtes et de sondages effectués aux États-Unis et au Canada.

L'étude des mesures et programmes mis sur pied dans les grandes entreprises américaines peut favoriser l'émergence de solutions pour le contexte québécois, même et surtout si le système de santé et de services sociaux américain est tout à fait différent du nôtre. Au Canada, on constate que l'ampleur du problème est inconnue. L'État est très présent dans les services sociaux, et les attentes à l'égard de l'État sont fortes autant de la part de la population que des entreprises. On constate que les syndicats $\mathrm{n}^{\prime}$ ont pas été à l'avant-garde dans ce domaine, s'insurgeant contre l'ingérence de l'entreprise dans la vie privée des employés. Les résultats $d^{\prime}$ 'une étude exploratoire sur les programmes offerts dans une vingtaine d'entreprises canadiennes démontrent quand même qu'une tendance à aider les employés commence à se dessiner. Pour chacune des entreprises canadiennes étudiées, des programmes et mesures pour responsabilités familiales sont présentés en tableau, permettant ainsi au lecteur de constater que très peu de mesures sont établies pour un travailleur aidant naturel d'un adulte dépendant. Les auteurs concluent sur la nécessité d'une lutte sur plusieurs fronts à la fois, les interventions devant viser l'équité dans le partage des responsabilités à l'égard des personnes dépendantes. Sinon, "les familles et les femmes en particulier continueront $d^{\prime}$ être réduites à combler les lacunes du système de santé et de services sociaux et à faire les frais de politiques déficientes plutôt que de devenir des partenaires à part entière...» (Guberman et al., 1993: 174).

Ce livre intéressera les gens soucieux de mieux comprendre la problématique de la prise en charge d'un dépendant même s'il est spécifiquement destiné aux experts du monde du travail, aux différents paliers de gouvernement, aux syndicats et à ceux qui doivent mettre en application les politiques et les programmes. 